\section{THE CROTON-OIL TREATMENT OF RING- WORM.}

To the Editor of THE LANCET.

SrR,-May I ask you kindly to publish this final reply to Mr. Cottle's letter in THE LANCET of April 17th. I thought my communication of the 10th inst. would have been sufficient. But as he still claims priority in bringing before the notice of the profession the croton-oil treatment of chronic ringworm, described in my paper in the January numbers of THE LANCET, I must, in justice to myself, say that the artificial production of kerion was the course I advocated; and as Mr. Cottle still affirms that a pustular rash is sufficient, and that the production of kerion is unnecessary, the matter is settled. I advised as my special treatment what he does not consider necessary.

I do not for one moment suppose I was the first to use croton oil for ringworm, or that Mr. Cottle was; but this I do assert, that I have been producing kerion with excellent results in inveterate ringworm during the last six years, having notes of cases which occurred in 1875. I did verbally bring my treatment under the notice of the profession three years ago, in a long conversation on the subject with the late Dr. Tilbury Fox. I also mentioned it in 1878 to Dr. Liveing, and other dermatologists ; and can prove that my paper has actually been written eighteen months. My reason for not publishing it sooner, was to give the croton-oil treatment a trial during another year, as well as the oleate of mercury.

I remain, Sir, yours obediently,

ALDER SMITH, M.B. LOND., F.R.C.S.

April 19th, 1880. Resident Medical Officer, Christ's Hospital.

P.S.-Will you allow me also to correct a mistake which is now prevalent-viz., that we have a number of ringworm cases at Christ's Hospital. Such is not the case. Our usual number is from $\frac{1}{2}$ to 1 per cent., while the percentage among boys brought to us for admission is 8.4 .

\section{PATHOLOGY OF SPIRILLUM FEVER. To the Editor of THE LANCET.}

Sir,-Adverting to the discussion at the Medico-Chirurgical Society, on my communication, as reported in THE LANCET of 28 th February, all I can say is that when they left me the microscopical preparations of the blood-spirillum were all clear, and two or three were even exquisite examples of the state of the blood in infected quadrumana.

I beg leave to observe that there is no possibility of an experienced eye mistaking the blood parasite for a common fungus.

To the best of my knowledge this organism is found only in famine or relapsing fever, pure or complicated. Its relationship to the pyrexia may not be immediate or direct, but within my experience spirillar infection of the blood has always culminated in a febrile attack.

I would here add that I have lately succeeded in inducing spirillum fever amongst the quadrumana by inoculating with infected blood taken during the prefebrile incubation period. This fact modifies one of my earlier conclusions. I am, Sir, your obedient servant

March 20th, 1880 H. V. CARTER.

\section{Gbituaty.}

WILLIAM SHARPEY, M.D., LL.D., F.R.S.

WilliaM ShaRPEy was born at Arbroath on April 1st, 1802, his father, an Englishman who had migrated from Folkestone to Arbroath, having died shortly before. For the first few hours after his birth his life was despaired of, and in after days he would humorously relate how the midwife, in the midst of the efforts made to insure his living, expressed in strong native accents, her opinion of the undesirability of these endeavours, since if the child lived it would be sure to prove an idiot. He learned the rudiments of the medical profession under Dr. Arrott of Arbroath, who had married his mother, and in 1817 entered the University of
Edinburgh, joining the medical classes in the following year, In 1821 he gained the diploma of the Royal College of Sur geons of Edinburgh, and in 1822 he came to London, wherefor some time he studied Anatomy in the school of the celebrated Brooks, in Windmill-street. The following winter be spent in Paris, and returning afterwards to Edinburgh, graduated in 1823, the subject of his thesis for the doctorate being "Cancer of the Stomach."

A part of the next few years of his life seems to hare been spent at Arbroath in private practice under his stepfather, Dr. Arrott, but his call in life at last came to him, and in 1827 he set out for the Continent, with the view partly of general culture, and partly of training himself for his future scientific career. He travelled through a large part of Crermanr; Switzerland, and Italy, performing his journeys for the most part on foot, bearing his knapsack, talking freely with the people among whom he passed, and gathering up that large fund of knowledge of men, places, and things which was one of the many striking features of his character. Part of the time spent abroad was, however, devoted to arduous scientific study. At Pavia under Panizza, and more especially at Berlin under Rudolphi, he dissected with great diligence, and made himself master of topographical Anatomy. The writer has often heard him speak of his time at Berlin as one of sustained and severe labour. It was undoubtedly there that he especially trained himself for his future career. He also passed some time in study at Paris, at Heidelberg under Tiedemann, and at Vienna. In 1829 he had returned to Edinburgh. In 1830 he became Fellow of the Edinburgh College of Surgeons, on which occasion he published an Inaugural Dissertation on the "Formation of False Joints after Resection." He also wrote at this time his first paper on "A Peculiar Motion in Animals, \&c.," published in the Edinburgh Medical and Surgical Journal, the researches described in which formed the basis of the well-known and able article "Cilia," which some years later appeared in Todd's Cyclopædia of Anatomy and Physiology.

In the autumn of 1831 he spent some time in Berlin, preparatory to beginning the teaching of Anatomy. This work he commenced in November of the same year as lecturer in the Extra-Academical School at Edinburgh, having his friend Allen Thomson for a colleague as lecturer on Physiology. He continued this labour until 1830, when he was appointed successor to Jones Quain in the chair of Anatomy and Physiology in what is now known as University College, London. This post he held for nearly forty years, not leaving it until 1874, when the increasiug infirmities of old age compelled his retirement. In 1850 he was appointed one of the Secretaries of the Royal Society, of which he had been made a Fellow in 1839, and the duties of this office also he resigned in 1874. The Baly medal of this Society was conferred upon him for Physiological research. In 1859 he was honoured with the degree of LL.D. by his own University of Edinburgh. He was long associated with the University of London, first as Examiner in Anatomy and Physiology, an office which he held more than once, and afterwards as Member of the Senate. He took an active part in the Rojal Commission on Science appointed in 1870. He was also a trustee of the Hunterian Museum, and sat for fifteen years in the General Medical Council as one of the Crown nominees. The Government recognised the long services of Dr. Sharpey by a warding him a pension of $£ 150$ a year.

But a few years ago William Sharpey seemed a hale and hearty man, and his massive frame, in spite of increasiug age. showed a vigour which seemed to promise still many years of usefulness. The onset of cataract first in one eye and then in the other, marked the first stages of his decay. The im. perfection in bis sight, together with some dulness in hearing, rendering him who had always been so self-reliant nore if less dependent on others, and thus interfering with the freedom of his movements, had a very markedly depressing effect on him. In the spring of 1879 , a severe attack of bronchitis, with alarming hæmorrhage, shook his constitution still further, and it was evident to his friends that he was gradually becoming more feeble. The greater part of last winter was spent in the mild air of Hastings, where he 